Original paper

\title{
Clinical Significance of Microvessel Count in Patients with Metastatic Liver Cancer Originated from Colorectal Carcinoma
}

\author{
Atsushi Nanashima, MD, ${ }^{1}$ Kenichirou Shibata, MD, ${ }^{1}$ Toshiyuki Nakayama, MD, ${ }^{2}$ \\ Syuuichi Tobinaga, MD, ${ }^{1}$ Masato Araki, MD, ${ }^{1}$ Masaki Kunizaki, MD, ${ }^{1}$ \\ Hiroaki Takeshita, MD, ${ }^{1}$ Shigekazu Hidaka, MD,${ }^{1}$ Terumitsu Sawai, MD, ${ }^{1}$ \\ and Takeshi Nagayasu MD, ${ }^{1}$
}

${ }^{1}$ Division of Surgical Oncology, Department of Translational Medical Sciences, Nagasaki University Graduate School of Biomedical Sciences, 1-7-1 Sakamoto, Nagasaki 852-8501, Japan

${ }^{2}$ Department of Molecular Pathology, Atomic Disease Institute, Nagasaki University Graduate School of Biomedical Sciences, 1-12-4 Sakamoto, Nagasaki 852-8523, Japan

Running head: MICROVESSEL COUNT IN METASTATIC LIVER CANCER

Address correspondence and reprint request to: Atsushi Nanashima, MD

Division of Surgical Oncology, Department of Translational Medical Sciences, Nagasaki University Graduate School of Biomedical Sciences, 1-7-1 Sakamoto, Nagasaki 8528501, Japan

Tel: +81-95-819-7304; Fax: +81-95-819-7306

E-mail: a-nanasm@,net.nagasaki-u.ac.jp

Key words: Metastatic liver carcinoma; Microvessel count; CD34; colorectal cancer Prognosis 


\begin{abstract}
Background: Microvessel count (MVC) was correlated with patient prognosis in hepatocellular carcinoma. We investigate whether the MVC using CD34 antibody was associated with the disease-free and overall survival in metastatic liver cancer (MLC) patients.
\end{abstract}

Methods: We examined relationships between MVC and clinicopathological factors or postoperative outcomes in 139 MLC patients who underwent hepatectomy between 1990 and 2006. CD34 expression was analyzed by the immunohistochemical method.

Results: MVC was associated with the fibrous pseudo-capsular formation by the histological examination. Using the modern Japanese classification of liver metastasis, poorer survival was associated with higher score, poorly differentiated adenocarcinoma, higher preoperative CEA level, fibrous pseudo-capsular formation and shorter surgical margin. Decreased disease-free survival was associated with higher score using the Japanese classification of liver metastasis, multiple or bi-lobar tumor, regional lymph node metastasis in primary colon carcinoma, preoperative CEA level, fibrous pseudo-capsular formation and shorter surgical margin $(<5 \mathrm{~mm})$. Higher MVC $\left(\geq 406 / \mathrm{mm}^{2}\right)$ was associated with decreased disease-free and overall survival by univariate analysis $(\mathrm{P}=0.034$ and $\mathrm{P}=0.021$, respectively $)$ and lower $\mathrm{MVC}$ represented an independent prognostic factor in overall survival by Cox's multivariate analysis (risk ratio, $2.71 ; \mathrm{P}=0.023)$, in addition to histological differentiation.

Conclusion: Tumor MVC appears to be a useful prognostic marker of MLC patient survival. 
Page 3

Nanashima et al.

\section{Synopsis}

Tumor microvessel count by immunohistochemical staining using CD34 antibody is a useful prognostic marker of overall survival in metastatic liver carcinoma patients who underwent hepatectomy. 
Hepatic resection is a useful option in the radical treatment of metastatic liver carcinoma (MLC). However, recurrence rates after resection remain high limiting patient survival. ${ }^{1,2}$ Some clinicopathological factors in MLC, specifically, tumor recurrence and tumor biological characteristics, provide useful information regarding tumor activity. ${ }^{3-5}$ According to previous reports, good potential candidates for molecular markers and tumor biological factors in MLC patients include lymphatic microvessel density (MVD) using CD31 antibody, ${ }^{7}$ doubling times, ${ }^{8}$ angiogenic factors, ${ }^{9}$ growth factors, ${ }^{10}$ abnormal expression of other oncogenes and suppressor genes such as TP53, ${ }^{6}$ and carcinoembryonic antigen. ${ }^{11}$ The use of a combination of conventional clinicopathological factors and tumor biology may improve our prognostic ability in patients who undergo hepatectomy for MLC and may contribute to a better staging system.

Tumor angiogenesis may be important in supporting tumor growth. ${ }^{12}$ Metastatic liver cancer also expresses angiogenic factors such as vascular endothelial growth factor (VEGF) and microvessel counts. ${ }^{9,13}$ Levels of these angiogenic factors may affect patient survival. ${ }^{9,13}$ Recent studies have shown that microvessel density (MVD) in MLC correlates with tumor aggressiveness and prognosis. ${ }^{13}$ Using multivariate analysis, we have already shown that higher microvessel count (MVC) using CD34 antibody is independently associated with poorer prognosis in MLC patients undergoing hepatic resection. ${ }^{14,15}$ Based on this prior work, we hypothesize that hypervascularity is a prognostic indicator of decreased survival in patients with MLC, since it is associated with tumor growth and invasion. 


\section{MATERIALS AND METHODS}

\section{Patients}

MLC specimens from 139 patients (93 men, 46 women) were excised during surgery performed on patients admitted to the Division of Surgical Oncology at Nagasaki University Graduate School of Biomedical Sciences (NUGSBS) between 1990 and 2006. The mean age for patients at the time of surgery was $62.6 \pm 12.3$ years (range, 24 - 85 years). Primary cancers included colon carcinomas in 75 patients and rectal carcinomas in 64 patients.

Patients with simultaneous liver metastasis who underwent resection of both the primary lesion and hepatectomy numbered 62 (45\%). 136 patients had a Child-Pugh classification of $\mathrm{A}$ and 3 patients $(2 \%)$ had a Child-Pugh classification of B. The operative procedures included hemihepatectomy or extended hemihepatectomy $(n=22)$, segmentectomy or sectionectomy $(\mathrm{n}=85)$ and partial resection $(\mathrm{n}=32)$. Radical hepatectomy was performed to remove hepatic tumor without leaving any residual tumor. All hepatic tumors were completely resected without macroscopic exposure of the amputated section to the remaining liver.

Patients undergoing additional ablation therapy were excluded from our series. All in-hospital deaths were excluded and only cancer-related death was included in our study. The minimum follow-up period after hepatic resection of HCC was 22 months. We used the classification system of the General Rules for the Clinical and Pathological Studies on Cancer of the Colon, Rectum and Anus by the Japanese Society for Cancer of the Colon and Rectum for clinicopathological evaluation ${ }^{16}$ and the $\mathrm{H}$ classification of Japan to evaluate the stage of liver metastasis (Table 1). ${ }^{16}$ All study protocols were approved by the Human Ethics Review Board of our institution. 
Informed consent for data collection was obtained from each patient during this period. Anesthesia data and patient data were retrieved from the NUGSBS database.

\section{Immunohistochemical staining}

Resected specimens were fixed in $10 \%$ formalin and embedded in paraffin. Thin sections $(4 \mu \mathrm{m})$ were deparaffinized twice using xylene and rehydrated in a series of ethanol solutions $(100 \%, 90 \%$ and $80 \%)$. Sections were placed in $0.01 \mathrm{~mol} / \mathrm{L}$ trisodium citrate dehydrate buffer $(\mathrm{pH} \mathrm{6.0)}$ ) and treated in a microwave oven for $10 \mathrm{~min}$ at $500 \mathrm{~W}$.

For CD34 staining, ${ }^{14,15}$ tissue sections were digested with $0.2 \%$ trypsin in 0.01 mol/L phosphate-buffered saline (PBS) for $20 \mathrm{~min}$ at $37^{\circ} \mathrm{C}$. The tissues were then immersed in $3 \% \mathrm{H}_{2} \mathrm{O}_{2}$ with distilled water for 10 min to inactivate endogenous peroxidases. After blocking non-specific binding by normal goat serum, sections were incubated overnight at $4^{\circ} \mathrm{C}$ with mouse anti-monoclonal CD34 antibody (1:25; QB-END/10, Novocastra Laboratories, Newcastle, United Kingdom) as the primary antibody. This was followed by reaction with biotinylated anti-immunoglobulin and reagent using labeled streptavidinbiotin (LSAB) kit peroxidase (Dako, Carpinteria, CA). The peroxidase reaction was visualized with $0.01 \% \mathrm{H}_{2} \mathrm{O}_{2}$ and 3, 3'-diaminobenzidine under light microscopy $(\times 200)$. For MVC using CD34 staining, average count was determined in the 5 most-vascular areas in the HCC examined at $200 \times$ magnification. ${ }^{14}$, ${ }^{15}$ Two pathologists blindly assessed each slide.

\section{Statistical analysis}

Continuous data were expressed as mean \pm standard deviation. Data from different groups were compared using one-way analysis of variance (ANOVA) and examined by 
Student's t-test or Dunnett's multiple comparison test. For univariate analysis, categorical data were analyzed using Fisher's exact test. Disease-free and overall survival rates were calculated according to the Kaplan-Meier method, and differences between groups were tested for significance using the log-rank test. Multivariate analysis was performed using proportional Cox's hazards regression modeling. A two-tailed value of $\mathrm{P}<0.05$ was considered statistically significant. All statistical analyses were performed using SAS software (Statistical Analysis System, Cary, NC). 


\section{RESULTS}

Among the 139 patients in the present study, overall 1-, 3-and 5-year survival rates were $76 \%, 48 \%$ and $36 \%$, respectively, and median overall survival was 65 months. Disease-free 1-, 3-and 5-year survival rates were $45 \%, 19 \%$ and $14 \%$, respectively, and median disease-free survival was 29 months. Of 100 patients $(71.9 \%)$ who displayed tumor recurrence after hepatectomy, $21(15.1 \%)$ received re-hepatectomy and 79 (56.8\%) received chemotherapy. Median MVC within the tumor area was $238 / \mathrm{mm}^{2}$, and this value was applied as the cut-off value.

Table 2 shows the relationship between microvessel count and clinicopathological features. MVC was significantly higher in tumors with fibrous pseudo-capsule formation compared to those tumors without this capsule. However, MVC was not associated with any other clinicopathological factor, $\mathrm{H}$ classification or postoperative recurrence rate.

Table 3 shows the relationship between disease-free or overall survival and clinicopathological factors including microvessel count. Preoperative carcinoembryonic antigen (CEA) level, $\mathrm{H}$ classification, number of tumors, tumor distribution and microvessel count were related to disease-free survival. $\mathrm{H}$ classification, histological differentiation, fibrous pseudo-capsule formation, surgical margin and MVC were associated with overall survival and this result was statistically significant. Fig. 1 shows disease-free and overall survival after hepatectomy compared to microvessel count. Disease-free survival rate was significantly lower in patients with higher microvessel count compared to patients with lower MVC using a cut-off level of 409/ $\mathrm{mm}^{2}$. Overall survival rates were also significantly lower in patients with higher MVC.

Table 4 shows the results of multivariate analysis for disease-free and overall survival 
after hepatectomy for various factors that showed significant association on univariate analysis. A higher level of preoperative CEA level was associated with lower disease-free survival after hepatectomy but this finding was not significant. On the other hand, poorly differentiated adenocarcinoma and higher microvessel density were identified as independent risk factors for lower overall survival after hepatectomy. 


\section{DISCUSSION}

Tumor angiogenesis is closely associated with tumor aggressiveness and poorer prognosis in patients with primary liver tumors ${ }^{14,15}$ and, therefore, this biological characteristic appears essential to hepatic tumor progression. Preliminary results from our study and other studies reveal that tumor angiogenesis has a significant impact on prognosis in patients with metastatic liver cancer who undergo radical hepatectomy. In addition, the tumor hypervascularity is associated with lower patient survival rates. ${ }^{16,17}$

Various angiogenic factors such as VEGF, Flk-1/KDR and flt-1 closely reflect tumor angiogenesis. $^{7,}$ 9, 18 Tumor angiogenesis, can also be easily examined using immunohistochemistry and, therefore, we propose its use in the pathologic evaluation of hepatic tumors.

From our clinical experience, metastatic liver cancer sometimes shows hypervascularity by the enhanced computed tomography or angiography and we examined the relationship between the tumor enhancement pattern using computed tomography and MVC and, however, we could not find any relationship between these two parameters by the preliminary data (not published yet). We originally hypothesized that there was a relationship between MVC, vascularity, and histological differentiation because previous studies showed a correlation between tumor angiogenesis and depth of invasion, lymphatic infiltration and lymph node metastasis in colorectal carcinoma patients with liver metastasis. ${ }^{19,20}$ Our results showed, however, that MVC was not associated with any clinicopathological parameters of metastatic liver cancer and the meaning of increased microvessel count, at the biologic level, is still unknown at this stage. Although we also examined the significance of MVC in the intrahepatic cholangiocarcinomas, which have a similar morphology to MLC, no relationship with 
pathological characteristics or patient prognosis after surgery was found. ${ }^{21}$

Based on our preliminary data, we focused on the association between MVC and post-hepatectomy outcomes and, therefore, we continued to add patients to the study and prolonged the follow-up period for these patients. In our analysis of survival, several associated tumor parameters, including microvessel count, were revealed upon review of the surgical records and these findings are in agreement with previous reports. $^{3-13,17}$

Since 1978, factors predictive of patient prognosis have been proposed by many investigators (see Table 5). ${ }^{22-30}$ However, any consensuses have yet to be achieved at this stage. As shown in both our preliminary data and our final results, higher microvessel count is associated with shorter disease-free periods and shorter overall survival times in patients with metastatic liver cancer undergoing hepatectomy. ${ }^{17,18}$ The multivariate analysis for patient prognosis, however, showed that only the preoperative CEA level was associated with disease-free survival, however this result was not significant. No factors including MVC were considered independent risk factors of tumor-free survivals in the present study.

Previous reports showed that candidate factors associated with recurrence of MLC included intrahepatic lymphatic invasion, fibrous capsule formation and oncogenes. ${ }^{31-33}$ In a previous report, higher microvessel count was found to be independently associated with poorer prognosis. ${ }^{34} \mathrm{MVC}$ would seem to be a useful predictive marker for patient survival after hepatectomy. Tumor vascularity may be correlated with proliferative activity or invasiveness of MLC. We plan to investigate this further as part of our future research.

Based on future studies using longer follow-up periods, we plant to consider 
additional anti-angiogenic treatment after hepatectomy. At this stage, some anti-angiogenic drugs, including bevacizumab for colorectal liver carcinoma, have been developed ${ }^{35,36}$ and applied in the clinical setting. ${ }^{37,38}$ In cases were tumor angiogenesis is strongly associated with patient survival, anti-angiogenic drugs could be used more aggressively. Based on our present findings, we hope to examine the survival benefit of adjuvant bevacizumab chemotherapy after radical hepatectomy to clarify the efficacy of MVC. MVC may become a selection marker in determining the need for adjuvant chemotherapy using anti-angiogenic drugs.

In conclusion, we have demonstrated that higher microvessel count, as identified by CD34 antibody levels in metastatic liver cancer patients, is an independent predictor of overall survival in these patients. As a tumor biological factor, MVC (representing tumor angiogenesis) appears to be a practical alternative for predicting tumor recurrence and survival in patients with metastatic liver cancer. Furthermore, this factor can hopefully be applied as a predictive marker in selecting anti-angiogenesis treatments in the future. 


\section{REFERENCES}

1. Jaeck D, Oussoultzoglou E. Intrahepatic lymphatic invasion independently predicts poor survival and recurrences after hepatectomy in patients with colorectal carcinoma liver metastases. Ann Surg Oncol. 2007;14:3297-3298.

2. Kato T, Yasui K, Hirai $\mathrm{T}$, et al. Therapeutic results for hepatic metastasis of colorectal cancer with special reference to effectiveness of hepatectomy: analysis of prognostic factors for 763 cases recorded at 18 institutions. Dis Colon Rectum. 2003; 46 (Suppl):S22-31.

3. Sasaki A, Iwashita Y, Shibata K, Matsumoto T, Ohta M, Kitano S. Analysis of preoperative prognostic factors for long-term survival after hepatic resection of liver metastasis of colorectal carcinoma. J Gastrointest Surg. 2005; 9:374-380.

4. Kokudo N, Miki Y, Sugai S, et al. Genetic and histological assessment of surgical margins in resected liver metastases from colorectal carcinoma: minimum surgical margins for successful resection. Arch Surg. 2002; 137:833-840.

5. Nanashima A, Yamaguchi H, Sawai T, et al. Expression of adhesion molecules in hepatic metastases of colorectal carcinoma: relationship to primary tumours and prognosis after hepatic resection. J Gastroenterol Hepatol. 1999; 14:1004-1009.

6. Molleví DG, Serrano T, Ginestà MM, et al. Mutations in TP53 are a prognostic factor in colorectal hepatic metastases undergoing surgical resection. Carcinogenesis. 2007; 28:1241-1246.

7. Saad RS, Kordunsky L, Liu YL, Denning KL, Kandil HA, Silverman JF. Lymphatic microvessel density as prognostic marker in colorectal cancer. Mod Pathol. 2006; 19:1317-1323. 
8. Tanaka K, Shimada H, Fujii Y, et al. Pre-hepatectomy prognostic staging to determine treatment strategy for colorectal cancer metastases to the liver. Langenbecks Arch Surg. 2004;389:371-379.

9. Onogawa S, Kitadai Y, Tanaka S, Kuwai T, Kimura S, Chayama K. Expression of VEGF-C and VEGF-D at the invasive edge correlates with lymph node metastasis and prognosis of patients with colorectal carcinoma. Cancer Sci. 2004;95:32-39.

10. Barozzi C, Ravaioli M, D'Errico A, et al. Relevance of biologic markers in colorectal carcinoma: a comparative study of a broad panel. Cancer. 2002;94:647-657.

11. Ito K, Hibi K, Ando $\mathrm{H}$, et al. Usefulness of analytical CEA doubling time and half-life time for overlooked synchronous metastases in colorectal carcinoma. Jpn J Clin Oncol. 2002;32:54-58.

12. Thelen A, Scholz A, Benckert C, et al. VEGF-D promotes tumor growth and lymphatic spread in a mouse model of hepatocellular carcinoma. Int $\mathrm{J}$ Cancer. 2008;122:2471-2481.

13. Ueda $\mathrm{T}$, Oda $\mathrm{T}$, Kinoshita $\mathrm{T}$, et al. Neovascularization in pancreatic ductal adenocarcinoma: Microvessel count analysis, comparison with non-cancerous regions and other types of carcinomas. Oncol Rep. 2002;9:239-245.

14. Pang RW, Joh JW, Johnson PJ, Monden M, Pawlik TM, Poon RT. Biology of hepatocellular carcinoma. Ann Surg Oncol. 2008;15:962-971.

15. Sun B, Zhang S, Zhang D, et al. Vasculogenic mimicry is associated with high tumor grade, invasion and metastasis, and short survival in patients with hepatocellular carcinoma. Oncol Rep. 2006;16:693-698.

16. Nanashima A, Ito M, Sekine I, et al. Significance of angiogenic factors in liver 
metastatic tumors originating from colorectal cancers. Dig Dis Sci. $1998 ; 43: 2634-2640$.

17. Nanashima A, Yamaguchi H, Sawai T, et al. Prognostic factors in hepatic metastases of colorectal carcinoma: immunohistochemical analysis of tumor biological factors. Dig Dis Sci. 2001;46:1623-1628.

18. Japanese Society for Cancer of the Colon and Rectum. 3.2.2 In: Mutoh T ed. General Rules for Clinical and Pathological Studies on Cancer of the Colon, Rectum and Anus (in Japanese). 7th ed. Tokyo: Kanehara \& Co., Ltd.; 2006, 14-15.

19. Nash AD, Baca M, Wright C, Scotney PD. The biology of vascular endothelial growth factor-B (VEGF-B). Pulm Pharmacol Ther. 2006;19:61-69.

20. Takeda A, Shimada H, Imaseki H, et al. Clinical significance of serum vascular endothelial growth factor in colorectal cancer patients: correlation with clinicopathological factors and tumor markers. Oncol Rep. 2000;7:333-338.

21. Nanashima A, Yoshinaga M, Yamaguchi H, et al. An immunohistochemical study of tumor vascularity and proliferation activity in cholangiocellular carcinoma: Relationship to clinicopathologic factors and prognosis after hepatic resection. Acta Med Nagasaki 2003;48;23-27.

22. Fortner JG, Silva JS, Golbey RB, et al. Multivariate analysis of a personal series of 247 consecutive patients with liver metastases from colorectal cancer. I. Treatment by hepatic resection. Ann Surg 1984;199:306-316.

23. Iwatsuki S, Esquivel CO, Gordon RD, et al. Liver resection for metastatic colorectal cancer. Surgery 1986;100:804-810.

24. Nordlinger B, Guiguet M, Vaillant JC, et al. Surgical resection of colorectal carcinoma metastases to the liver. A prognostic scoring system to improve case 
selection, based on 1568 patients. Association Francaise de Chirurgie. Cancer $1996 ; 77: 1254-1262$.

25. Jaeck D, Bachellier P, Guiguet M, et al. Long-term survival following resection of colorectal hepatic metastases. Association Francaise de Chirurgie. Br J Surg 1997;84:977-980.

26. Cady B, Jenkins RL, Steele GD Jr, et al. Surgical margin in hepatic resection for colorectal metastasis: a critical and improvable determinant of outcome. Ann Surg $1998 ; 227: 566-571$.

27. Fong Y, Fortner J, Sun RL, et al. Clinical score for predicting recurrence after hepatic resection for metastatic colorectal cancer: analysis of 1001 consecutive cases. Ann Surg 1999;230:309-318.

28. Minagawa M, Makuuchi M, Torzilli G, et al. Extension of the frontiers of surgical indications in the treatment of liver metastases from colorectal cancer: long-term results. Ann Surg 2000;231:487-499.

29. Choti MA, Sitzmann JV, Tiburi MF, et al. Trends in long-term survival following liver resection for hepatic colorectal metastases. Ann Surg 2002;235:759-766.

30. Nagashima I, Takada T, Matsuda K, et al. A new scoring system to classify patients with colorectal liver metastases: proposal of criteria to select candidates for hepatic resection. J Hepatobiliary Pancreat Surg. 2004;11:79-83.

31. Korita PV, Wakai T, Shirai Y, et al. Intrahepatic lymphatic invasion independently predicts poor survival and recurrences after hepatectomy in patients with colorectal carcinoma liver metastases. Ann Surg Oncol. 2007;14:3472-3480.

32. Okano K, Yamamoto J, Kosuge T, et al. Fibrous pseudocapsule of metastatic liver tumors from colorectal carcinoma. Clinicopathologic study of 152 first resection 
cases. Cancer. 2000;89:267-275.

33. Kokudo N, Miki Y, Sugai S, et al. Genetic and histological assessment of surgical margins in resected liver metastases from colorectal carcinoma: minimum surgical margins for successful resection. Arch Surg. 2002;137:833-840.

34. Nagashima I, Takada T, Matsuda K, et al. A new scoring system to classify patients with colorectal liver metastases: proposal of criteria to select candidates for hepatic resection. J Hepatobiliary Pancreat Surg 2004;11:79-83.

35. Chan LS, Malcontenti-Wilson C, Muralidharan V, Christophi C. Effect of vascular targeting agent Oxi4503 on tumor cell kinetics in a mouse model of colorectal liver metastasis. Anticancer Res. 2007;27:2317-2323.

36. Duff SE, Jeziorska M, Rosa DD, et al. Vascular endothelial growth factors and receptors in colorectal cancer: implications for anti-angiogenic therapy. Eur $\mathrm{J}$ Cancer. 2006;42:112-117.

37. Board RE, Valle JW. Metastatic colorectal cancer: current systemic treatment options. Drugs. 2007;67:1851-1867.

38. Tappenden P, Jones R, Paisley S, Carroll C. Systematic review and economic evaluation of bevacizumab and cetuximab for the treatment of metastatic colorectal cancer. Health Technol Assess. 2007;11:1-128. 


\section{FIGURE LEGEND}

Fig.1. Disease-free and overall survivals after hepatectomy in patients with metastatic liver carcinoma compared to microvessel count. Cut-off level of MVC was set at a 409/mm². A solid line shows a lower MVC and a dotted line shows a higher MVC. 
TABLE 1. Definition and criteria used in the original and revised H-number grading system for liver metastasis.

H-number system ${ }^{\dagger}$

HX Liver metastasis, unknown

H0 No liver metastasis

H1 Some metastases ( $\leq 4$ lesions) and size of the largest tumor $\leq 5 \mathrm{~cm}$

H2 Except H1, H3

H3 Some metastases $(\geq 5)$ and size of the largest tumor $>5 \mathrm{~cm}$

'; the H-number of General Rules for Clinical and Pathologic studies on Cancer of the Colon, Rectum and Anus in $2006{ }^{18}$ 
TABLE 2. Relationship between microvessel density and clinicopathological factors in $M L C$

\begin{tabular}{|c|c|c|}
\hline & Microvessel count $\left(/ \mathrm{mm}^{2}\right)$ & $\mathrm{P}$ value \\
\hline \multicolumn{3}{|l|}{ Gender } \\
\hline Male/Female & $225 \pm 106 / 250 \pm 138$ & 0.60 \\
\hline \multicolumn{3}{|l|}{ Age } \\
\hline$>60 \mathrm{y} \cdot \mathrm{o} / \leq 60 \mathrm{y} \cdot \mathrm{o}$ & $252 \pm 125 / 227 \pm 113$ & 0.34 \\
\hline \multicolumn{3}{|l|}{ Preoperative CEA } \\
\hline$<15 \mathrm{ng} / \mathrm{ml} / \geq 15 \mathrm{ng} / \mathrm{ml}$ & $219 \pm 107 / 220 \pm 123$ & 0.95 \\
\hline \multicolumn{3}{|l|}{ Node status of primary carcinoma } \\
\hline No/Yes & $238 \pm 105 / 239 \pm 119$ & 0.67 \\
\hline \multicolumn{3}{|l|}{ Time of liver metastasis } \\
\hline Synchronous/Metachronous & $249 \pm 107 / 225 \pm 120$ & 0.12 \\
\hline \multicolumn{3}{|l|}{ Number of tumor } \\
\hline Solitary/Multiple & $224 \pm 119 / 242 \pm 120$ & 0.49 \\
\hline \multicolumn{3}{|l|}{ Location of tumor } \\
\hline Unilobar / Bilobar & $225 \pm 105 / 263 \pm 131$ & 0.36 \\
\hline \multicolumn{3}{|l|}{ H classification } \\
\hline $\mathrm{H} 1 / \mathrm{H} 2 / \mathrm{H} 3$ & $224 \pm 112 / 238 \pm 125 / 275 \pm 143$ & 0.48 \\
\hline \multicolumn{3}{|l|}{ Histological differentiation } \\
\hline Well/Moderately/Poorly & $200 \pm 56 / 238 \pm 120 / 300 \pm 144$ & 0.23 \\
\hline \multicolumn{3}{|l|}{ Vascular invasion } \\
\hline No/Yes & $213 \pm 138 / 220 \pm 118$ & 0.68 \\
\hline \multicolumn{3}{|c|}{ Fibrous pseudo-capsular formation } \\
\hline $\mathrm{No} / \mathrm{Yes}$ & $237 \pm 121 / 256 \pm 100$ & 0.43 \\
\hline \multicolumn{3}{|l|}{ Postoperative tumor recurrence } \\
\hline $\mathrm{No} / \mathrm{Yes}$ & $224 \pm 94 / 250 \pm 116$ & 0.46 \\
\hline
\end{tabular}


TABLE 3. Relationship between clinicopathological factors and survival rates in $M L C$

\begin{tabular}{|c|c|c|c|c|}
\hline & $\begin{array}{c}\text { Disease-free survival } \\
\text { rates }(5 \text { years: } \%)\end{array}$ & $\mathrm{P}$ value & $\begin{array}{l}\text { Overall survival } \\
\text { rates (5 years: } \% \text { ) }\end{array}$ & $P$ value \\
\hline \multicolumn{5}{|l|}{ Gender } \\
\hline Male/Female & $10 / 16$ & 0.13 & $39 / 36$ & 0.81 \\
\hline \multicolumn{5}{|l|}{ Age (years) } \\
\hline$>60 \quad / \leq 60$ & $11 / 17$ & 0.10 & $25 / 42$ & 0.11 \\
\hline \multicolumn{5}{|l|}{ Preoperative CEA (ng/ml) } \\
\hline$>15 / \leq 15$ & $23 / 10$ & 0.010 & $38 / 31$ & 0.084 \\
\hline \multicolumn{5}{|l|}{ Node status of primary cancer } \\
\hline No / Yes & $34 / 8$ & 0.088 & $49 / 30$ & 0.12 \\
\hline \multicolumn{5}{|l|}{ Time of liver metastasis } \\
\hline Simultaneous/Metachronous & $19 / 8$ & 0.87 & $39 / 33$ & 0.37 \\
\hline \multicolumn{5}{|l|}{ Number of tumor } \\
\hline $1 / \geq 2$ & $24 / 6$ & 0.009 & $40 / 34$ & 0.26 \\
\hline \multicolumn{5}{|l|}{ Size of tumor $(\mathrm{mm})$} \\
\hline$<50 / \geq 50$ & $17 / 13$ & 0.78 & $35 / 41$ & 0.94 \\
\hline \multicolumn{5}{|l|}{ Distribution } \\
\hline Unilobar / Bilobar & $24 / 6$ & 0.002 & $41 / 28$ & 0.045 \\
\hline \multicolumn{5}{|l|}{$\mathrm{H}$ classification } \\
\hline $\mathrm{H} 1 / \mathrm{H} 2 / \mathrm{H} 3$ & $28 / 0 / 8$ & $<0.001$ & $48 / 21 / 21$ & 0.018 \\
\hline \multicolumn{5}{|l|}{ Histological differentiation } \\
\hline Well/Moderately/Poorly & $18 / 14 / 12$ & 0.30 & 47 / $42 / 17$ & 0.033 \\
\hline \multicolumn{5}{|l|}{ Vascular invasion } \\
\hline No / Yes & $33 / 8$ & 0.47 & $34 / 21$ & 0.36 \\
\hline \multicolumn{5}{|c|}{ Fibrous pseudo-capsular formation } \\
\hline No / Yes & $14 / 25$ & 0.066 & $21 / 69$ & 0.005 \\
\hline \multicolumn{5}{|l|}{ Microvessel counts, CD34(/mm²) } \\
\hline$<238 / \geq 238$ & $19 / 0$ & 0.034 & $42 / 13$ & 0.022 \\
\hline \multicolumn{5}{|l|}{ Surgical margin (mm) } \\
\hline$<5 \quad / \quad \geq 5$ & $9 / 22$ & 0.079 & $24 / 48$ & 0.011 \\
\hline \multicolumn{5}{|l|}{ Postoperative chemotherapy } \\
\hline No / Yes & $21 / 13$ & 0.82 & $38 / 37$ & 0.78 \\
\hline
\end{tabular}

CEA: carcinoembryonic antigen 
TABLE 4. Multivariate analysis by Cox's proportional hazard test of prognostic factors influencing disease-free survival and overall survival in MLC after hepatectomy

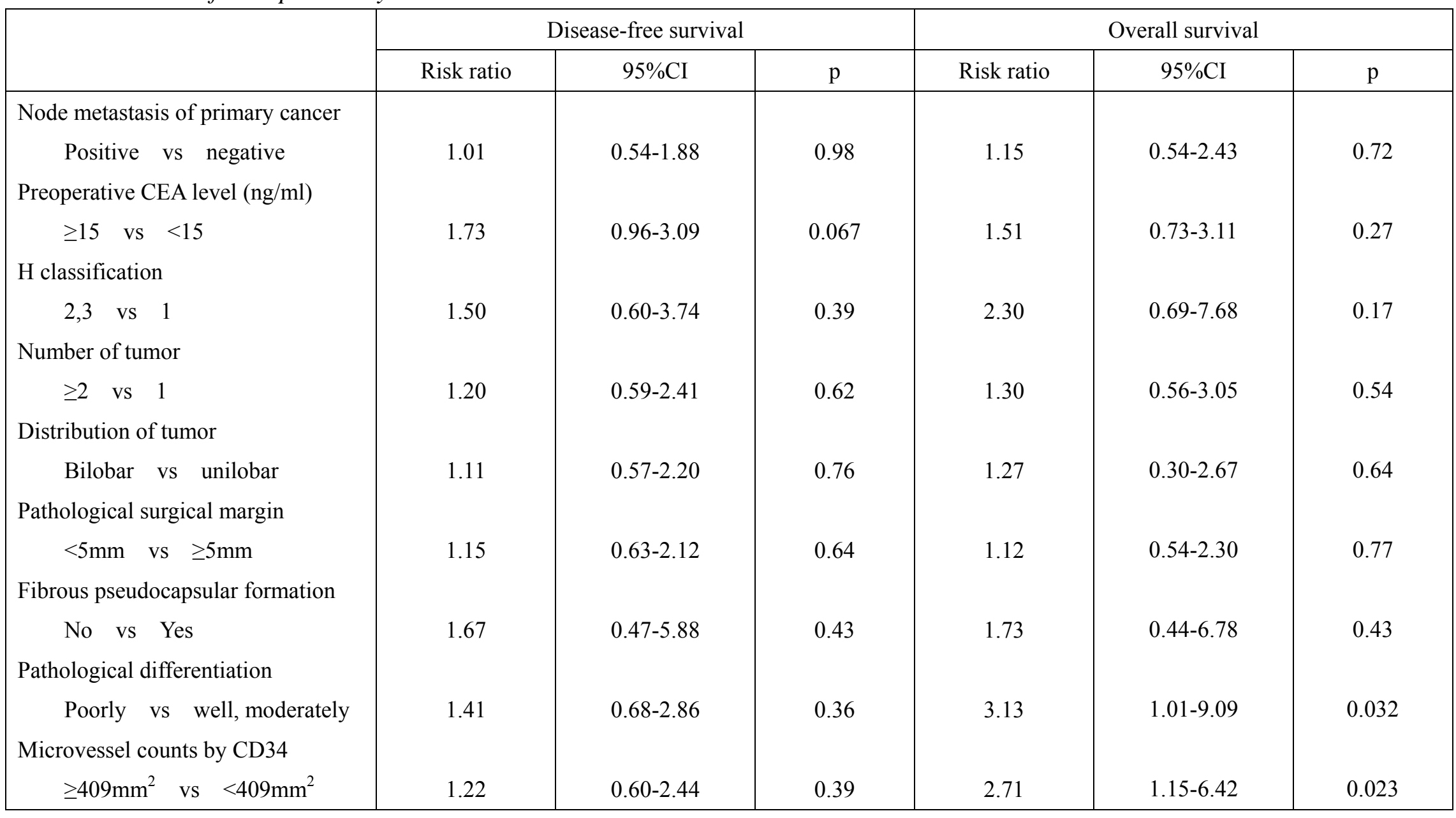

CEA: Carcinoembryonic antigen 
TABLE 5. Predictors of tumor recurrence after hepatectomy in metastatic liver cancer reported in previous studies.

\begin{tabular}{|c|c|c|c|c|c|c|c|c|c|c|c|c|c|c|c|}
\hline & \multicolumn{5}{|c|}{ Primary } & \multicolumn{9}{|c|}{ Metastasis } & \multirow[b]{2}{*}{$\begin{array}{c}\text { Surgical } \\
\text { Margin or } \\
\text { Incomplete } \\
\text { Resection }\end{array}$} \\
\hline & Age & Stage & Site & $\begin{array}{c}\text { Node } \\
\text { Status }\end{array}$ & $\begin{array}{l}\text { Tumor } \\
\text {-free } \\
\text { period }\end{array}$ & $\begin{array}{c}\text { Synchro- } \\
\text { nous }\end{array}$ & CEA & Size & No. & $\begin{array}{l}\text { Distri- } \\
\text { bution }\end{array}$ & $\begin{array}{c}\text { Vessel } \\
\text { invasion }\end{array}$ & $\begin{array}{l}\text { Node } \\
\text { in } \\
\text { hilum }\end{array}$ & $\begin{array}{c}\text { Extra- } \\
\text { hepatic } \\
\text { Metastasis }\end{array}$ & $\begin{array}{l}\text { Operative } \\
\text { Procedure }\end{array}$ & \\
\hline Fortner 1984 22) & $\mathrm{N}$ & $\mathrm{Y}$ & & & & & $\mathrm{N}$ & $\mathrm{N}$ & $\mathrm{N}$ & & & & & & \\
\hline Iwatsuki $1986^{23)}$ & $\mathrm{N}$ & $\mathrm{Y}$ & & & & & & & $\mathrm{Y}$ & & & & & & $\mathrm{Y}$ \\
\hline Nordlinger 1996 24) & $\mathrm{Y}$ & $\mathrm{Y}$ & $\mathrm{Y}$ & & $\mathrm{Y}$ & $\mathrm{Y}$ & $\mathrm{Y}$ & $\mathrm{Y}$ & $\mathrm{Y}$ & $\mathrm{N}$ & & & & $\mathrm{N}$ & $\mathrm{Y}$ \\
\hline Jaeck 1997 25) & & $\mathrm{Y}$ & & & $\mathrm{N}$ & & $\mathrm{N}$ & $\mathrm{N}$ & $\mathrm{N}$ & $\mathrm{N}$ & & & & $\mathrm{N}$ & $\mathrm{Y}$ \\
\hline Cady $1998^{26)}$ & & $\mathrm{N}$ & & & $\mathrm{Y}$ & & $\mathrm{Y}$ & $\mathrm{N}$ & $\mathrm{Y}$ & $\mathrm{N}$ & & & & & $\mathrm{Y}$ \\
\hline Fong 1999 27) & $\mathrm{N}$ & $\mathrm{Y}$ & $\mathrm{N}$ & $\mathrm{Y}$ & $\mathrm{Y}$ & & $\mathrm{Y}$ & $\mathrm{Y}$ & $\mathrm{Y}$ & $\mathrm{Y}$ & & & $\mathrm{Y}$ & $\mathrm{Y}$ & $\mathrm{Y}$ \\
\hline Minagawa 2000 28) & $\mathrm{N}$ & $\mathrm{Y}$ & $\mathrm{N}$ & & $\mathrm{N}$ & $\mathrm{N}$ & $\mathrm{N}$ & $\mathrm{N}$ & $\mathrm{Y}$ & $\mathrm{N}$ & $\mathrm{N}$ & $\mathrm{Y}$ & $\mathrm{N}$ & $\mathrm{N}$ & $\mathrm{N}$ \\
\hline Choti 2002 29) & & $\mathrm{N}$ & & & $\mathrm{N}$ & $\mathrm{N}$ & $\mathrm{Y}$ & $\mathrm{N}$ & $\mathrm{N}$ & $\mathrm{N}$ & & & & $\mathrm{N}$ & $\mathrm{Y}$ \\
\hline Nagashima 2004 30) & & $\mathrm{Y}$ & & $\mathrm{Y}$ & & & & $\mathrm{Y}$ & $\mathrm{Y}$ & & & & $\mathrm{Y}$ & & \\
\hline
\end{tabular}

$\mathrm{Y}:$ yes, N: no 
Fig. 1
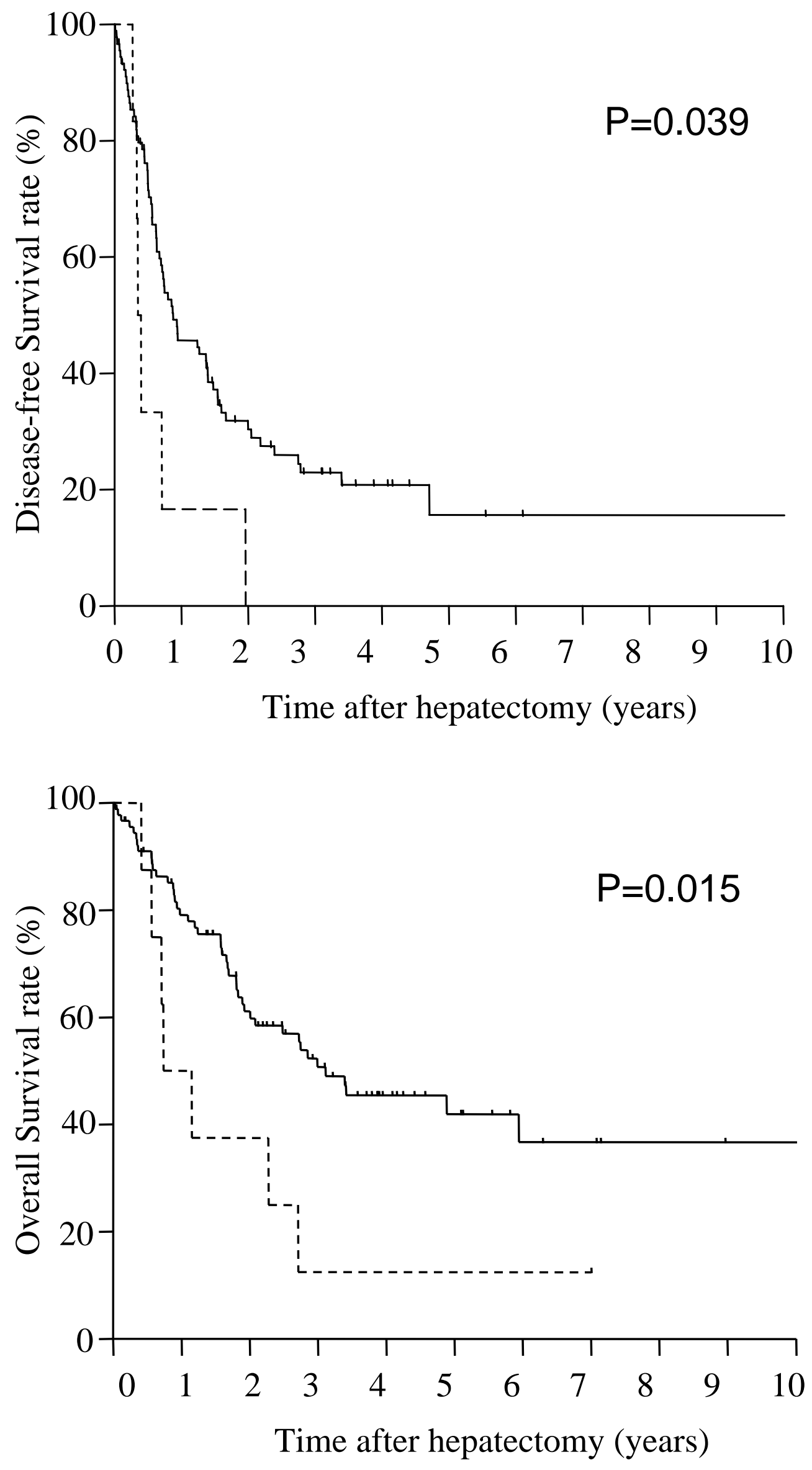